\title{
Effect of Rosemary and Sweet Marjoram on three Predacious Mites of the Family Phytoseiidae (Acari: Phytoseiidae)
}

\author{
F. M. MOMEN and S. A. A. AMER \\ Pests and Plants Protection Department, National Research Center, \\ Dokki-Cairo, Egypt
}

\begin{abstract}
The direct toxicity of two essential oils, Majorana hortensis, Moench and Rosmarinus officinalis L. to adult females of the predacious mites, Amblyseius zaheri Yousef and El-Borolossy, Amblyseius barkeri (Hughes) and Typhlodromus athiasae Porath and Swirski were tested. Rosemary oil was the most toxic to females of A. barkeri and the least to A. zaheri. In contrast, sweet marjoram oil was relatively toxic to T. athiasae and slightly toxic to A. barkeri. Both essential oils, decreased the food consumption rate at the concentration used for A. barkeri and A. zaheri. Females of A. barkeri and A. zaheri suffered a depression in reproduction when treated with $1 \%$ of rosemary oil. Both material used seems to be harmless to T. athiasae at $1 \%$.
\end{abstract}

Key words: Acari: Amblyseius barkeri, Amblyseius zaheri, essential oils, Typhlodromus athiasae.

The predacious mites, Amblyseius barkeri (Hughes), Amblyseius zaheri Yousef and El-Borolossy and Typhlodromus athiasae Porath and Swirski, have played an important role in biological control of the spider mites, Tetranychus urticae Koch and Eutetranychus orientalis (Klein) in Egypt (Momen, 1995, Abou-Elella, 1998, Momen and ElBorolossy, 1999, Zaher et al., 1999). There was a critical need to test pesticides for their side effects on beneficial organisms which are present along with the target pest (Theiling and Croft, 1988). The use of chemical pesticides offers problems such as atmospheric pollution and residual toxicity in food, therefore research on the anti-feedants, which often derived from plants is needed. Among these botanicals, Majorana hortensis Moench and Rosemarinus officinalis L. which are considered as two of the most valuable aromatic and medicinal plants. The first report from Egypt by (Amer et al., in prep.) demonstrated that, both above materials are potent mite repellent and antifeedant for $E$. orientalis and $T$. urticae. The effect of $M$. hortensis and $R$. officinalis on the predacious mites has not been studied before. However a few studies on Neem extracts and other types of plant extracts have been conducted on phytoseiid mites such as Euseius scutalis Athias-Henriot (=Amblyseius gossipi El-Badry), T. athiasae, A. barkeri, Amblyseius swirskii (A. H.), A. zaheri and Typhlodromus exhilaratus Ragusa (Dimetry and Amer, 1992; Mansour et al., 1993; Dimetry et al., 1994; Momen and Amer, 1994; Momen et al., 1997; Tsolakis et al., 1997).

This is the second report from Egypt on essential oils, was undertaken to provide information on the direct effect of $M$. hortensis and $R$. officinalis on the predacious mites, A. barkeri, A. zaheri and T. athiasae in the laboratory. 


\section{Materials and Methods}

\section{Maintenance of mite stock cultures}

The stock cultures of T. urticae were collected from infested lima bean (Phaseolus vulgaris L.) in the laboratory at N. R. C. Cairo. The predacious mites A. zaheri and A. barkeri were found on leaves of eggplant and cucumber and were fed $T$. urticae in the laboratory. T. athiasae was collected from an apple orchard and reared on eggs and immature stages of T. urticae. The mites were kept in a controlled climate room at $25-27^{\circ} \mathrm{C}$ and $60 \pm 5 \%$ R. H.

\section{Preparation of the material tested}

Both oils, $R$. officinalis and $M$. hortensis were extracted by submitting the air dried herb of each steam distillation for 3 hours in Clevenger apparatus. The oil was collected from each kind was dehydrated over anhydrous sodium sulphate.

\section{Treatment}

Effect of $\mathrm{R}$. officinalis and $\mathrm{M}$. hortensis oils on adult females of some predacious mites

Each adult females of 3 predators species (A. zaheri, A. barkeri and T. athiasae) were confined separately on the lower surfaces of detached raspberry leaves ( $3 \mathrm{~cm}$ in dia.) while the upper surfaces were placed on cotton saturated with water. Predacious mites were sprayed using a glass atomizer. Each test contained 5 concentrations and each concentration had 4 replicates ( 20 females/replicate). In every test, a water control was included. Mortality was recorded $48 \mathrm{~h}$ after application. Corrected mortality counts according to Abbott's formula (1925), were statistically analysed by (Finney, 1952).

Effect of $\mathrm{R}$. officinalis and M. hortensis oils on adult fecundity, sex ratio and consumption of treated predacious mites

Newly emerged and mated females of 3 predator species were treated with a concentration (1\%), which has been proved to be effective against T. urticae (Amer et al., in prep.). Females transferred singly to the lower surface of raspberry leaf discs and were provided daily with a sufficient known number of $T$. urticae nymph for 1 week. A control treatment was included in each test for different predators. Observation were taken daily on consumption, reproduction, mortality and sex ratio of the progeny for 7 successive days. Statistical analysis were carried out using the "F" test. Calculation of the adverse effect of different extracts on the predators was done according to the formula of (Overmeer and Van Zon, 1982). According to (Hassan, 1985), the adverse effect (E) of the treatment was classified to the following categories:

$$
\begin{array}{lll}
\text { 1. } & \mathrm{E}=0-25 \% & \text { harmless. } \\
\text { 2. } & \mathrm{E}=26-50 \% & \text { slightly harmful. } \\
\text { 3. } & \mathrm{E}=51-75 \% & \text { moderately harmful. } \\
\text { 4. } & \mathrm{E}=76-100 \% & \text { harmful. }
\end{array}
$$


The percentage of reduction in food consumption was calculated according to (Samsoe-Petersen, 1983).

\section{Results and Discussion}

Effect of $\mathrm{R}$. officinalis and $\mathrm{M}$. hortensis oils on adult females of some predacious mites

Figures 1 and 2 show the relation between the percentage of mortality and the concentrations of both rosemary and sweet marjoram oils on adult females of A. barkeri, A. zaheri and T. athiasae. The data obtained in Fig. 1 shows that rosemary oil was the most toxic to females of $A$. barkeri and the least toxic to females of $A$. zaheri.

Based on the $\mathrm{LC}_{50}$ value of rosemary oil, toxicity were in an ascending order as follows (9.91, 5.80 and 4.34\%, respectively) for A. zaheri, T. athiasae and A. barkeri.

Results from Fig. 2 shows that sweet marjoram oil was relatively the most toxic to females of T. athiasae and the least toxic to females A. barkeri. The results indicated also that both materials tested, had similar toxicity effect on $T$. athiasae $\left(\mathrm{LC}_{50}: 5.80\right.$ and $5.32 \%$ for rosemary and sweet marjoram oils, respectively). Mansour et al. (1993) revealed that RD9 - Repelin was highly toxic to T. athiasae, but Margosan-O and Azatin were not toxic.

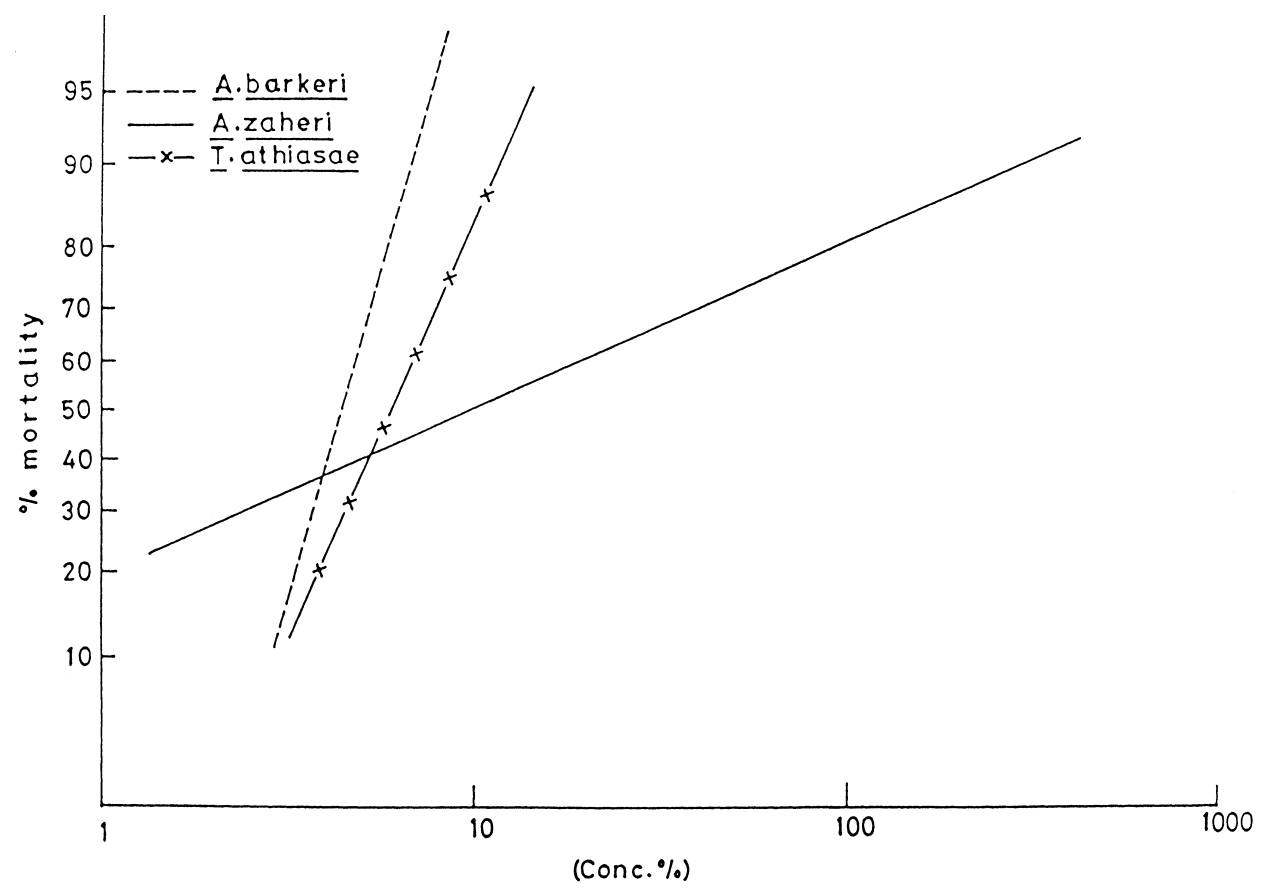

Fig. 1. Toxicity of rosemary oil against adult females of the predacious mites,

A. barkeri, A. zaheri and T. athiasae 


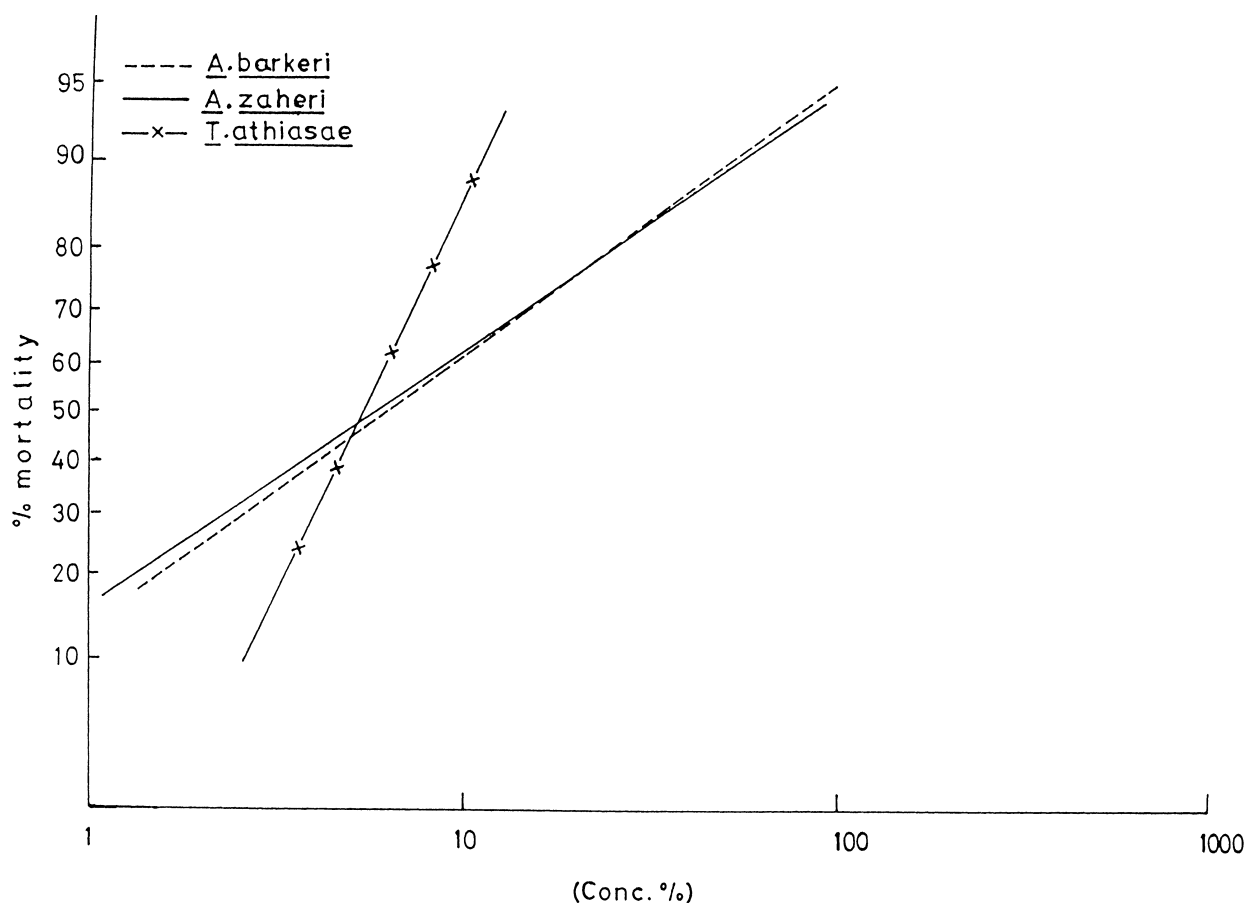

Fig. 2. Toxicity of sweet marjoram oil against adult females of the predacious mites,

A. barkeri, A. zaheri and T. athiasae

In previous studies by (Momen and Amer, 1994), it was shown that lupin extract was slightly toxic to eggs and females of A. barkeri, while fenugreak, canna and turnip extracts were not toxic for the predator.

Effect of $\mathrm{R}$. officinalis and $\mathrm{M}$. hortensis oils on adult fecundity, sex ratio and consumption of treated predacious mites

Results from Table 1 show that a significant lower consumption rate were recorded at conc. $1 \%$ on treated adult females of $A$. zaheri and A. barkeri with rosemary and sweet marjoram oils. The percentage of reduction in the food consumption decreased to 8.75 and $13.09 \%$ for both above oils for T. athiasae. Momen et al. (1997) reported a significant lower consumption at conc. $0.2 \%$ on treated females of A. zaheri and A. barkeri when exposed to nymphs of $T$. urticae formerly kept together on plant leaves treated with Neem-Azal-F. Similar result was recorded also on A. barkeri when kept on treated leaves with lupin extract, Margosan-O and Neem-Azal-S (Momen and Amer, 1994; Dimetry et al., 1994).

Results from Table 2 show that both rosemary and sweet marjoram oils appeared to be harmless for $T$. athiasae as no significant reduction in fecundity was recorded. In addition, mortalities was $5 \%$ after 1 week treatment, with both oils. The adverse effect of both materials was slightly harmful on $A$. zaheri and A. barkeri $(\mathrm{E}<50 \%)$. Both oils used 


\section{Table 1}

Effect of rosemary and sweet marjoram on the food consumption of A. zaheri, A. barkeri and T. athiasae

\begin{tabular}{lccc}
\hline Treatments & Total prey/Female/7days & Total prey/Female/day & \% Reduction in food consumption \\
\hline & & A. zaheri & \\
Rosemary & 68.2 & 9.74 & 18.81 \\
Sweet marjoram & 72.7 & 10.39 & 13.45 \\
Control & 84.0 & 12.0 & \\
0.05 & & 0.834 & \\
L.S.D. & & & \\
0.01 & & 1.143 & \\
& & A. barkeri & \\
Rosemary & 89.6 & 12.8 & - \\
Sweet marjoram & 98.4 & 14.06 & \\
Control & 131.9 & 18.84 & \\
0.05 & & 1.051 & \\
L.S.D. & & & \\
0.01 & & 1.440 & \\
& & & \\
& & T. athiasae & \\
Rosemary & 75.65 & 10.81 & \\
Sweet marjoram & 72.05 & 10.29 & \\
Control & 82.9 & 11.84 & \\
0.05 & & 1.142 & \\
L.S.D. & & 1.564 & \\
0.01 & & & \\
\hline
\end{tabular}

were caused (10-20\%) mortalities, respectively, on adult females of A. barkeri tested after 1 week treatment.

Results obtained in Table 2 show also a significant reduction in the total number of eggs laid/female during 7 days period for A. zaheri and A. barkeri in case of rosemary oil at conc. $1 \%$. Previous studies by (Momen et al., 1997) demonstrated that Neem AzalF appeared to be harmless for A. barkeri and A. zaheri. Again A. barkeri suffered a drop in reproduction when fed on prey kept on treated leaves with lupin, turnip and fenugreek extracts (Momen and Amer, 1994). Studies by various authors revealed that some toxicants had no immediate effect on predacious mites but reproduction might be disturbed (van de Vrie, 1962; Daneshvar, 1963; El-Banhawy, 1976). Neither egg hatchability nor the sex-ratio of the progeny were affected by both oils tested on phytoseiids. The sex ratio was tended in favour of females. 
Table 2

Effect of rosemary and sweet marjoram on the reproduction, mortality and sex-ratio of the progeny of treated females of A. zaheri, A. barkeri and T. athiasae

\begin{tabular}{|c|c|c|c|c|c|}
\hline Treatments & $\begin{array}{l}\text { Total No. Eggs/ } \\
\text { Female/7 days }\end{array}$ & $\begin{array}{c}\text { No eggs/ } \\
\text { Female/day }\end{array}$ & $\begin{array}{l}\% \text { M. after } \\
7 \text { days }\end{array}$ & $\begin{array}{c}\text { \% Adverse } \\
\text { effect }\end{array}$ & $\begin{array}{c}\text { Sex-ratio } \\
\text { male : female }\end{array}$ \\
\hline & & & A. zaheri & & \\
\hline Rosemary & 9.65 & 1.38 & 5 & 30.55 & $1: 2.6$ \\
\hline Sweet marjoram & 10.05 & 1.44 & 5 & 27.67 & $1: 2.3$ \\
\hline Control & 13.2 & 1.89 & 0 & - & $1: 2.4$ \\
\hline 0.05 & & 0.351 & & & \\
\hline \multicolumn{6}{|l|}{ L.S.D. } \\
\hline \multirow[t]{2}{*}{0.01} & & 0.481 & & & \\
\hline & & & A. barkeri & & \\
\hline Rosemary & 14.45 & 2.06 & 10 & 31.55 & $1: 2.2$ \\
\hline Sweet marjoram & 17.15 & 2.45 & 20 & 27.79 & $1: 3.1$ \\
\hline Control & 19.0 & 2.71 & 0 & - & $1: 3.0$ \\
\hline 0.05 & & 0.440 & & & \\
\hline \multicolumn{6}{|l|}{ L.S.D. } \\
\hline \multirow[t]{2}{*}{0.01} & & 0.602 & & & \\
\hline & & & T. athiasae & & \\
\hline Rosemary & 13.2 & 1.89 & 5 & 24 & $1: 1.8$ \\
\hline Sweet marjoram & 14.65 & 2.09 & 5 & 15.65 & $1: 2.1$ \\
\hline Control & 16.5 & 2.36 & 0 & - & $1: 2.1$ \\
\hline 0.05 & & 0.518 & & & \\
\hline \multicolumn{6}{|l|}{ L.S.D. } \\
\hline 0.01 & & 0.618 & & & \\
\hline
\end{tabular}

\section{Conclusions}

Our results indicated that both oils used which were toxic to the pest T. urticae are satisfactory for the predator T. athiasae. The use of a botanical pesticide that is relatively nontoxic to natural enemies could increase the effectiveness of natural predation. T. athiasae is a key predator of spider mites in deciduous orchards, vineyards and vegetable field (Swirski et al., 1967). Therefore the work presented here is based on laboratory data, which are not always directly transferable to the field. Therefore, is should be mentioned that the use of anti-feedants as practical pest control agents requires considerable experimentation and developments. UV-light, rain fall, temperature, and perhaps $\mathrm{PH}$ value on treated leaves are important environmental factors when both oils are applied for pest control in the field.

Field trials are therefore necessary in order to determine the effect of both oils $R$. officinalis and M. hortensis will have on T. athiasae, A. barkeri and A. zaheri and other phythoseiid populations in crop fields and apple orchards. 


\section{Literature}

Abbott, W. S. (1925): A method of computing the effectiveness of an insecticide. J. Econ. Entomol. 18 (2), $265-267$.

Abou-Elella, G. M. (1998): Studies on certain aspects of some predacious phytoseiid mites. Ph.D. Thesis, Cairo University $183 \mathrm{pp}$.

Daneshvar, H. (1963): Einfluss einger Pflanzenshutzmittel auf die Raubmilbe Typhlodromus (Typhlodromus) pyri Scheuten (Acari: Phytoseiidae). Diss. Landwirtch. Hochsch. Hohenheim. 74.

Dimetry, N. Z. and Amer, S. A. A. (1992): Effect of some plant extracts on the predatory efficiency of Amblyseius gossipi El-Badry (Acari: Phytoseiidae). Afr. J. Agric. Sci. 19 (2), 99-110.

Dimetry, N. Z., Amer, S. A. A. and Momen, F. M. (1994): Laboratory trials of two neem seed extracts on the predatory mites Amblyseius barkeri (Hughes) and Typhlodromus richteri. Karg. Boll. Zool. Agr. Bachic. $26(1), 127-137$.

El-Banhawy, E. M. (1976): Residual toxicity of some common acaricides in Brazil to the predacious mite Amblyseius brazilli. Entomophaga 21 (3), 303-306

Finney, D. J. (1952): Probit analysis a statistical treatment of the sigmoid response curve. Cambridge Univ. Press.

Hassan, S. A. (1985): Standard method to test the side effects of pesticides on natural enemies of insects and mites developed by the IOBC/WPRS working group „Pesticides and Beneficial organisms“. EPPO Bull. 15, 214-255.

Mansour, F. A., Ascher. K. R. S. and Abo-Moch, F. (1993): Effects of Margosan-OTM, AzatinTM and RD9 Repelin on spider, and on predacious and phytophagous mites. Phytoparasatica 21, 205-211.

Momen, F. M. (1995): Feeding, development and reproduction of Amblyseius barkeri (Acarina: Phytoseiidae) on various kinds of food substances. Acarologia 36 (2), 101-105.

Momen, F. M. and Amer, S. A. A. (1994): Effect of some foliar extracts on the predatory mite Amblyseius barkeri (Acarina: Phytoseiidae). Acarologia 35 (3), 223-228.

Momen, F. M. and El-Borolossy, M. (1999): Suitability of the citrus brown mite, Eutetranychus orientalis as prey for nine species of phytoseiid mites (Acari, Tetranychidae, Phytoseiidae). Acarologia 40 (1), in press.

Momen, F. M., Reda, A. S. and Amer, S. A. A. (1997): Effect of Neem Azal-F on Tetranychus urticae and three predacious mites of the family phythoseiidae. Acta Phytopathologica et Entomologica Hungarica 32 (3-4), 355-362.

Overmeer, W. P. J. and Van Zon, A. G. (1982): A standard method for testing the side effects of pesticides on the predacious mite Amblyseius potentillae (Acarina: Phytoseiidae). Entomophaga 27, 357-364.

Samsoe-Petersen, L. (1983): Laboratory method for testing side effects of pesticides on juvenile stage of the predatory mite, Phytoseiulus persimilis (Acarina: Phytoseiidae) based on detached bean leaves. Entomophaga 28, 167-178.

Swirski, E., Amitai, S. and Dorzia, N. (1967): Laboratory studies on the feeding, development and oviposition of the predacious mite Typhlodromus athiasae P. and S. (Acarina: Phytoseiidae) on various kinds of food substances. Isr. J. Agric. Res. 17 (4), 213-218.

Theiling, K. M. and Croft, B. A. (1988): Pesticide side-effects on arthropod natural enemies; a database summary. Agric. Ecosystems Environ. 21, 191-218.

Tsolakis, H., Leto, G. and Ragusa, S. (1997): Effects of some plant materials on Tetranychus urticae Koch (Acariformes, Tetranychidae) and Typhlodromus exhilaratus Ragusa (Parasitiformes, Phytoseiidae). ANPP-Fourth International Conference on Pests in Agriculture Montpellier 6-7-8 January 1977, 239-245.

van de Vrie, M. (1962): The influence of spray chemicals on predatory and phytophagus mites on apple trees in laboratory and field trials in the Netherlands. Entomophaga 7 (3), 243-250.

Zaher, M. A., Nawar, M. S., Abou-Setta, M. M. and Ibrahim Abla, A. (1999): Effect of some biotic and abiotic factors on the biology of Typhlodromus athiasae (Acari: Phytoseiidae). Acarologia 40, in press. 